\title{
Assessment of drought tolerance in barley: integrated selection criterion and drought tolerance indices
}

\author{
Marouf Khalili', Alireza Pour-Aboughadareh², Mohammad Reza Naghavi ${ }^{\text {* }}$ \\ ${ }^{1}$ Department of Agriculture, Payame Noor University, PO BOX 19395-3697 Tehran, Iran \\ ${ }^{2}$ Department of Plant Breeding and Crop Production, Imam Khomeini International University, PO BOX 34149 - 16818, Qazvin, Iran \\ *Corresponding author, E-mail: mr_naghavi@ymail.com
}

\begin{abstract}
Although drought stress is the most serious problem affecting barley production, progress in the development of resistant cultivars is limited due to the lack of effective selection criteria. The objectives of this study were (i) to selection drought tolerant barley lines based on agro-morphological traits and tolerance indices and (ii) to assess use-efficiency of integrated selection criterion in screening of tolerance lines across multi-environments. For these purposes, 40 doubled haploid lines along with parental genotypes were grown during two consecutive years (2013-2014) under different water regimes at the Research Station of Mahabad Payame-Noor University and Miandoab Agricultural Research Station, West Azerbaijan, Iran. According to combined analysis of variance, in both locations a large significant difference was observed among lines for most of the studied traits indicating that selection in this materials would be useful. Correlation coefficients (for two years and two locations) indicated significantly positive relation between different tolerance indices and integrated selection criterion with grain yields under non-stress and stress conditions. Multivariate analysis and threedimensional graphs showed that integrated selection criterion index, similar to other indices, was able to distinguish the tolerant and desirable lines across multiple environments. Finally, our results indicated that doubled haploid lines numbers L3, L13, L18, L29 and L35 were desirable lines for both conditions.
\end{abstract}

Key words: barley, water deficit stress, drought tolerance indicators, integrated selection, multivariate analysis.

Abbreviations: GMP, geometric mean production; MP, mean production; PCA, principal components analysis; SI, integrated selection criterion; SSI, stress susceptibility index; STI, stress tolerance index; YSI, yield stability index.

\section{Introduction}

One of the great challenges facing economies and societies over the next decades is feeding the population, and providing water resources to produce food for a world that is experiencing a rapid population growth in a time of global climate change (Dorostkar et al. 2015). Barley (Hordeum vulgare L.) is a major crop ranked fourth in the worldwide production of cereals. This crop is considered as a primary staple food in the semi-arid tropics of Asia, Africa, and South America. Barley grain is usually used as food and animal fodder, and moreover as raw material for the production of beer (Pour-Aboughadareh et al. 2013). The improvement of crops requires the creation and introduction of a variant genetic resource, as well as, inbreeding coupled with evaluation of breeding materials and extensive selection in different environments to identify adapted and stable genotypes. In plant breeding programmes, the production of doubled haploid lines provides one of the easiest and fastest techniques of obtaining completely homozygous progenies from selected crosses (Choo et al. 1985).

Water deficit or drought stress is one of the most common environmental stresses that affects growth and development of plants. In other words, this stress is a permanent constraint to agricultural production in many countries, and an occasional cause of losses of agricultural production (Pour-Siahbidi et al.2013). The success of barley breeding programs is largely due to its good capacity and stability to yield well under drought and poor management conditions where other crops would fail. Some researchers believe in selection under favorable conditions (Betran et al. 2003; Richard 1996) and some believe in selection under typical drought conditions (Ceccarelli 1987; Ceccarelli, Grando 1991). Nevertheless, there exist numerous researchers that chose the midway and believe in selection under both favorable and stressed conditions (Clark et al. 1992; Fernandez 1992). To differentiate drought tolerance genotypes, several selection indices have been used on the basis of both grain yield under normal and stressed conditions (Fischer, Maurer 1978; Lin, Binns 1988).

Indices such as stress tolerance index (STI), geometric mean productivity (GMP), and yield stability index (YSI) have been used for comparing genotypic performance across years or environments (Sio-Se Mardeh et al. 2006); however, Saba et al. (2001) recommended that STI might be better used in plant breeding programmes, because of its moderate heritability and the inherent ability of 
screening high yielding genotypes in either non-stressed or stressed conditions. Recently, Hao et al. (2011) introduced a new selection criterion to assess response of genotypes to drought stress across multiple environments. They declared that this new index, integrated selection criterion (SI), provides an estimate of drought stress resistance based on grain yield and related agronomic characters, and thus it would be useful in identifying excellent drought-resistant genotypes in breeding programmes. We hypothesized that the selected lines have significant diversity in terms of agromorphological traits. However, to provide more knowledge for selecting of lines as well as determining contribution of each trait to drought tolerance, we aimed to assess the effects of drought stress on agro-morphological traits in 40 doubled haploid lines and also to evaluate use-efficiency of integrated selection criterion in screening of tolerance lines across different environments.

\section{Materials and methods}

\section{Plant material, design and experimental sites}

The plant material used in this work consisted of 40 doubled haploid lines along with parental genotypes. These materials were evaluated during two consecutive cropping seasons at two locations and under two different water regimes. These doubled haploids derived from a cross between cv. 'Morex' (resistance to drought stress) and cv. 'Steptoe' (susceptible to drought stress) genotypes. The cross was carried out in a barley breeding programme at Oregon University (North American Barley Genome Mapping Project).

Field experiments were conducted at two research stations, Miandoab Agricultural Research Station and Research Station of Mahabad Payame-Noor University, in West Azerbaijan Province (northwest of Iran) during 2012-2013 and 2013-2014 cropping seasons. Based on DeMartonne classification, these experiment sites are located in semi-arid regions of Iran. The first station (1371 m above sea level, $46^{\circ} 09^{\prime} \mathrm{N}$, and $36^{\circ} 58^{\prime} \mathrm{E}$ ) had $289 \mathrm{~mm}$ annual rainfall on a long-term average. In both experiment sites the soil texture was silt-clay-loam (30\% clay, $52 \%$ silt and $18 \%$ sand) with $\mathrm{pH}$ of 8.05 . Available $\mathrm{P}$ and $\mathrm{K}$ were 6.69 and $314 \mathrm{ppm}$, respectively. The second station, (1371 m above sea level, $45^{\circ} 43^{\prime} \mathrm{N}, 36^{\circ} 1^{\prime} \mathrm{E}$ ) had $326 \mathrm{~mm}$ annual rainfall on a long-term average. The soil texture was silt-clay-loam (30\% clay, $54 \%$ silt and $16 \%$ sand) with $\mathrm{pH}$ of 8.09 . Available P and $\mathrm{K}$ were 14.62 and $444 \mathrm{ppm}$, respectively.

In each of the areas, 40 lines along with three checks and parental genotypes were planted in a randomized complete block design with two replications and grown under two water regimes. Sowing was done by hand in November in all experiments. Plots consisted of four, 2.5-m-long rows spaced $25 \mathrm{~cm}$ apart. Fertilizer was applied before sowing ( 80 $\mathrm{kg} \mathrm{ha}^{-1} \mathrm{P}_{2} \mathrm{O}_{5}$ and $50 \mathrm{~kg} \mathrm{ha}^{-1} \mathrm{KNO}_{3}$ ) and at stem elongation $\left(100 \mathrm{~kg} \mathrm{ha}^{-1} \mathrm{CH}_{4} \mathrm{~N}_{2} \mathrm{O}\right.$ ).

The plants were grown under two moisture regimes of irrigation after $90 \mathrm{~mm}$ and $190 \mathrm{~mm}$ evaporation from a class-A pan for normal and drought-stress conditions, respectively. The drought-stress treatments were applied from the booting stage till physiological maturity. Crop management practices such as pest and weed control and plant nutrition were practiced as needed during the growing season.

The following agro-morphological characteristics were recorded: plant height $(\mathrm{cm})$, peduncle length $(\mathrm{cm})$, number of spikes (per $\left.1 \mathrm{~m}^{2}\right)$, spike length $(\mathrm{cm})$, number of grains per spike, 1000-grains weight $(\mathrm{g})$, hectoliter grain weight $(\mathrm{kg})$, grain yield $\left(\mathrm{kg} \mathrm{ha}^{-1}\right)$, biological yield $\left(\mathrm{kg} \mathrm{ha}^{-1}\right)$ and harvest index. Ten randomly chosen plants from each plot were used for recording data on agro-morphological characters.

\section{Data analysis}

Combined analysis of variance (ANOVA) was performed using SAS software (SAS, 1987). Five drought resistance indices including stress tolerance index (STI), mean production (MP), geometric mean production (GMP), stress susceptibility (SSI), and yield stability index (YSI), were calculated using the following relationships (Fischer, Maurer 1978; Rosielle, Hamblin 1981; Fernandez 1992; Gavuzzi et al. 1997):

$$
\begin{gathered}
\mathrm{STI}=\frac{\mathrm{Y}_{\mathrm{p}}+\mathrm{Y}_{\mathrm{s}}}{\overline{\mathrm{Y}}_{\mathrm{p}}^{2}}, \\
\mathrm{MP}=\frac{\mathrm{Y}_{\mathrm{p}}+\mathrm{Y}_{\mathrm{s}}}{2}, \\
\mathrm{GMP}=\sqrt{\left(\mathrm{Y}_{\mathrm{p}} \times \mathrm{Y}_{\mathrm{s}}\right)}, \\
\mathrm{SSI}=\frac{1-\left(\mathrm{Y}_{\mathrm{s}} / \mathrm{Y}_{\mathrm{p}}\right)}{1-\left(\overline{\mathrm{Y}_{\mathrm{s}}} / \overline{Y_{\mathrm{p}}}\right)}, \\
\mathrm{YSI}=\frac{\mathrm{Y}_{\mathrm{s}}}{\mathrm{Y}_{\mathrm{p}}},
\end{gathered}
$$

where $Y_{p}$ is particular yield in non-stress conditions, $Y_{s}$ is particular yield in stress conditions, $\bar{Y}_{p}$ is mean yield in non-stress conditions, $\bar{Y}_{s}$ is mean yield in stress conditions.

The integrated selection index (SI) was calculated according to Hao et al. (2011) on the basis of the obtained results from factor analysis for agro-morphological traits under non-stress and water deficit stress conditions using the following steps:

$$
\begin{gathered}
\mathrm{S}_{\mathrm{ij}}=\left(\mathrm{X}_{\mathrm{ij}}-\mu_{\mathrm{j}}\right) / \sigma_{\mathrm{j}}, \\
\mathrm{MP}_{\mathrm{ij}}=\left(\mathrm{S}_{\mathrm{ijd}}+\mathrm{S}_{\mathrm{ijw}}\right) / 2, \\
\mathrm{SI}=b_{1} \mathrm{MP}_{\mathrm{i} 1}+b_{2} \mathrm{MPi} 2+\ldots . .+b_{\mathrm{j}} \mathrm{MP}_{\mathrm{ij}},
\end{gathered}
$$

where $S_{i j}$ is the standardized agronomic value of the trait $j^{\text {th }}(j=1$ to 10$)$ in line $i^{\text {th }}$ under non-stress and droughtstress conditions, $X_{i j}$ is agro-morphological value of line $i^{\text {th }}$ on trait $j^{\text {th }}, \mu_{j}$ is mean value of trait $j^{\text {th }}$ in all of the lines, $\sigma_{j}$ is the standard deviation of the trait $j^{\text {th }}, \mathrm{MP}_{\mathrm{ij}}$ is the mean productivity of the trait $j^{\text {th }}$ on line $i^{\text {th }}, b_{j}$ is the weight value of the trait $j^{\text {th }} ; b_{j}$ was calculated from the average contribution to factor 1 . The contributions of each trait on factor 1 are 
Table 1. Contribution of factor 1 of agro-morphological traits related to drought resistance at eight environments in the factor analysis. $\mathrm{L}_{1}$ and $\mathrm{Y}_{1}$, first location and year; $\mathrm{L}_{2}$ and $\mathrm{Y}_{2}$, second location and year; $\mathrm{N}$ and $\mathrm{S}$, non-stress and stress conditions

$\begin{array}{lccccccccc}\text { Trait } & \mathbf{L}_{1} \mathbf{Y}_{1} \mathbf{N} & \mathbf{L}_{1} \mathbf{Y}_{1} \mathbf{S} & \mathbf{L}_{2} \mathbf{Y}_{1} \mathbf{N} & \mathbf{L}_{2} \mathbf{Y}_{1} \mathbf{S} & \mathbf{L}_{1} \mathbf{Y}_{2} \mathbf{N} & \mathbf{L}_{1} \mathbf{Y}_{2} \mathbf{S} & \mathbf{L}_{2} \mathbf{Y}_{2} \mathbf{N} & \mathbf{L}_{2} \mathbf{Y}_{2} \mathbf{S} & \text { Average } \\ \text { Plant height } & -0.04 & -0.62 & 0.04 & -0.44 & 0.04 & 0.08 & 0.06 & 0.16 & -0.09 \\ \text { Peduncle length } & 0.68 & 0.63 & 0.44 & 0.64 & 0.71 & 0.73 & 0.74 & 0.73 & 0.66 \\ \text { Spike length } & 0.50 & 0.12 & 0.71 & -0.01 & 0.56 & 0.51 & 0.57 & 0.57 & 0.44 \\ \text { Number of grains per spike } & 0.63 & 0.32 & 0.82 & 0.23 & 0.26 & 0.41 & 0.29 & 0.39 & 0.41 \\ \text { Number of spike } & -0.12 & -0.29 & 0.18 & -0.52 & 0.02 & -0.16 & 0.02 & -0.14 & -0.12 \\ \text { 1000-grains weight } & 0.87 & 0.90 & 0.07 & 0.74 & 0.91 & 0.93 & 0.93 & 0.92 & 0.78 \\ \text { Hectoliter grain weight } & 0.72 & 0.65 & 0.03 & 0.75 & 0.76 & 0.79 & 0.78 & 0.77 & 0.65 \\ \text { Grain yield } & 0.38 & 0.27 & 0.93 & 0.89 & 0.56 & 0.66 & 0.57 & 0.63 & 0.61 \\ \text { Biological yield } & 0.08 & 0.03 & 0.92 & 0.77 & 0.10 & 0.22 & 0.13 & 0.21 & 0.31 \\ \text { Harvest index } & 0.82 & 0.84 & 0.02 & 0.76 & 0.87 & 0.92 & 0.87 & 0.89 & 0.75\end{array}$

shown in Table 1. Multivariate analyses were also used for distinguishing drought tolerance lines and getting better understanding of relationships among grain yields and the drought tolerance indices. Principal components analysis (PCA) and biplot diagrams were used to identify tolerant and susceptible lines by Minitab software (Minitab 2004). For recognizing drought-tolerant and high-yielding lines in both conditions, three-dimensional graphs based on the best drought tolerance indices and grain yields were drawn using Statistica software (Statistica 2007).

\section{Results}

The results of multi-environment trials analysis for grain yield and agro-morphological traits in Miandoab and Mahabad stations are shown in Table 2. At both locations, there was a significant difference in the performance of lines for all evaluated traits. Also, there was a significant difference between years and water regime conditions for grain yield and other traits. At Miandoab station, the year $\times$ line interaction differed significantly for all of the traits except for grain yield and biological yield, whereas the line $\times$ water regime conditions had significant effect on all traits except 1000-grains weight and harvest index. On the other hand, at the Mahabad station, the results of analysis of variance were different in that the interaction between lines $\times$ year was highly significant for all of the traits studied. Additionally, the interaction between lines and water regime conditions was significant for plant height, grain yield and biological yield. Grain yield under non-stress condition was significantly correlated with grain yield under drought stress condition (Fig. 1). Yield performance of lines in nonstress condition ranged from 4256 to $7049 \mathrm{~kg} \mathrm{ha}^{-1}$, while under drought stress condition it varied from 3276 to 5144 $\mathrm{kg} \mathrm{ha}^{-1}$. Line L35 followed by L3 and L30 had the highest grain yield under both conditions. Lines L28 and L34 had poor performance under non-stress and stress conditions, while line L32 was highly adapted to the non-stressed conditions. Lines L6, L16 and L18 had a similar response to drought-stress conditions, however their response to nonstressed conditions differed and varied from 5475 to 6156 $\mathrm{kg} \mathrm{ha}^{-1}$ (Fig. 1). The biggest difference in yield performance

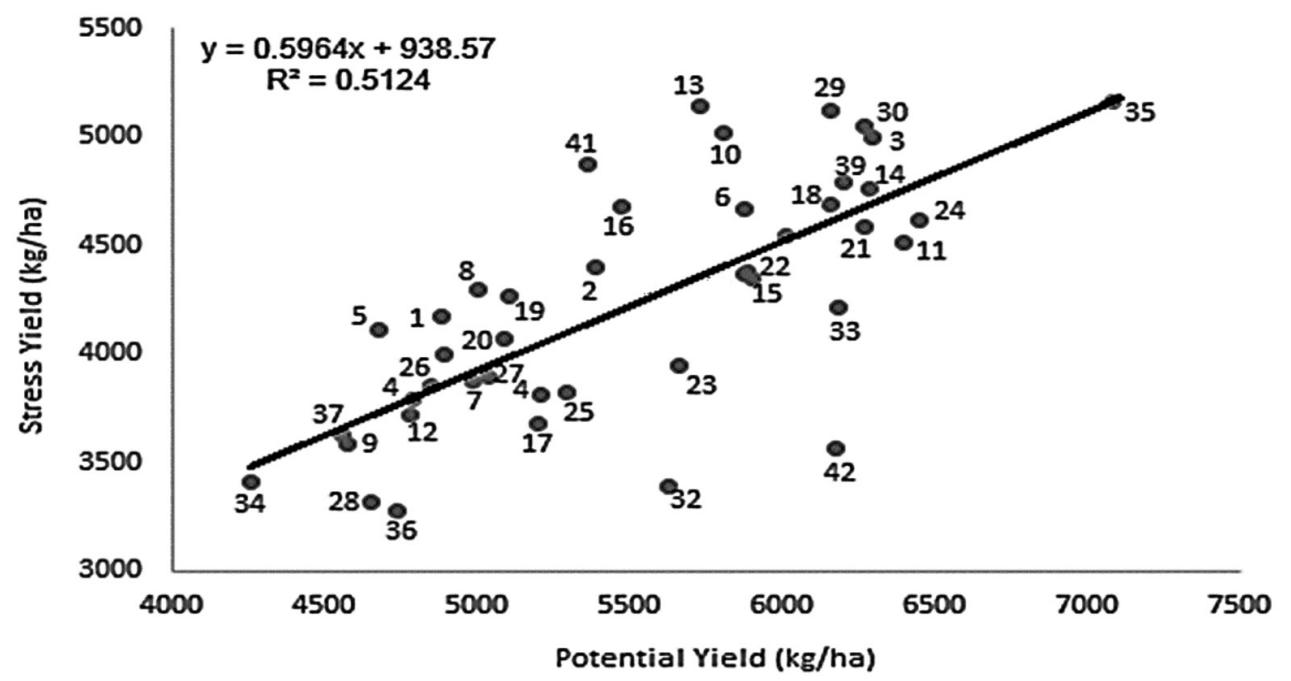

Fig. 1. Association between grain yield under non-stress and stress conditions in barley doubled haploid lines. Each point is the mean yield over the years and locations. 


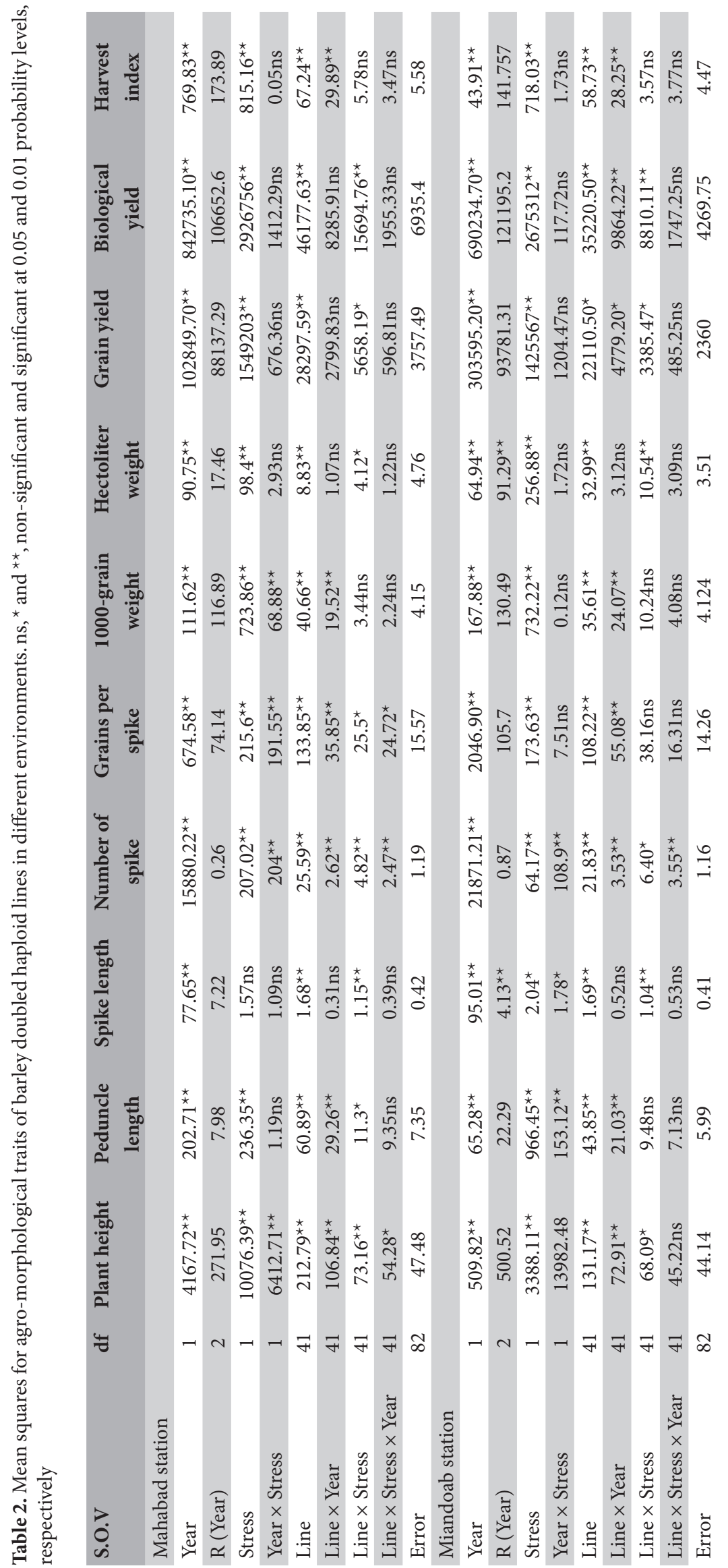


Table 3. Drought tolerance indices for barley doubled haploid lines (averaged over two years and two locations. Yp, grain yield under non-stressed conditions $\left(\mathrm{g} \mathrm{m}^{-2}\right)$; Ys, grain yield under stress conditions; SSI, stress susceptibility index; STI, stress tolerance index; MP, mean productivity; GMP, geometric mean productivity; YSI, yield stability index; SI, integrated selection index. LSD, least significant difference at 0.05 probability level

\begin{tabular}{|c|c|c|c|c|c|c|c|c|}
\hline Line & $Y p$ & Ys & SSI & STI & MP & GMP & YSI & SI \\
\hline L1 & 488.77 & 417.18 & 0.63 & 0.67 & 452.98 & 451.56 & 0.85 & -1.47 \\
\hline L2 & 538.67 & 439.75 & 0.79 & 0.78 & 489.21 & 486.70 & 0.82 & 0.92 \\
\hline L3 & 630.04 & 499.72 & 0.89 & 1.04 & 564.88 & 561.11 & 0.79 & 1.60 \\
\hline L4 & 479.26 & 379.21 & 0.89 & 0.60 & 429.24 & 426.31 & 0.79 & -4.06 \\
\hline L5 & 468.05 & 411.32 & 0.52 & 0.63 & 439.68 & 438.77 & 0.88 & -2.70 \\
\hline L6 & 587.33 & 466.63 & 0.88 & 0.90 & 526.98 & 523.51 & 0.79 & 2.32 \\
\hline L7 & 498.43 & 387.15 & 0.96 & 0.64 & 442.79 & 439.28 & 0.78 & -2.41 \\
\hline L8 & 500.70 & 429.18 & 0.61 & 0.71 & 464.94 & 463.56 & 0.86 & -0.51 \\
\hline L9 & 457.35 & 358.65 & 0.93 & 0.54 & 408.00 & 405.00 & 0.78 & -2.70 \\
\hline L10 & 581.26 & 501.88 & 0.59 & 0.96 & 541.57 & 540.12 & 0.86 & 2.06 \\
\hline L11 & 639.83 & 451.63 & 1.26 & 0.95 & 545.73 & 537.55 & 0.71 & -0.72 \\
\hline L12 & 478.45 & 372.23 & 0.95 & 0.59 & 425.34 & 422.01 & 0.78 & -2.70 \\
\hline L13 & 573.38 & 514.44 & 0.44 & 0.97 & 543.91 & 543.11 & 0.90 & 1.22 \\
\hline L14 & 628.97 & 476.00 & 1.04 & 0.99 & 552.49 & 547.17 & 0.76 & 2.04 \\
\hline L15 & 589.88 & 434.46 & 1.13 & 0.84 & 512.17 & 506.24 & 0.74 & -0.06 \\
\hline L16 & 547.57 & 467.19 & 0.63 & 0.84 & 507.38 & 505.79 & 0.85 & -1.44 \\
\hline L17 & 520.16 & 367.77 & 1.26 & 0.63 & 443.97 & 437.38 & 0.71 & -2.97 \\
\hline L18 & 615.61 & 469.05 & 1.02 & 0.95 & 542.33 & 537.35 & 0.76 & 0.91 \\
\hline L19 & 510.60 & 426.33 & 0.71 & 0.72 & 468.47 & 466.57 & 0.83 & -1.36 \\
\hline L20 & 509.36 & 407.04 & 0.86 & 0.68 & 458.20 & 455.33 & 0.80 & -1.94 \\
\hline L21 & 627.17 & 458.01 & 1.16 & 0.95 & 542.59 & 535.96 & 0.73 & 1.12 \\
\hline L22 & 588.26 & 437.91 & 1.10 & 0.85 & 513.08 & 507.55 & 0.74 & 0.92 \\
\hline L23 & 566.65 & 394.43 & 1.30 & 0.74 & 480.54 & 472.76 & 0.70 & -3.24 \\
\hline L24 & 645.01 & 461.82 & 1.22 & 0.98 & 553.41 & 545.78 & 0.72 & 1.04 \\
\hline L25 & 529.23 & 381.82 & 1.19 & 0.67 & 455.53 & 449.53 & 0.72 & -2.63 \\
\hline L26 & 484.83 & 385.45 & 0.88 & 0.62 & 435.14 & 432.29 & 0.80 & -3.05 \\
\hline L27 & 503.73 & 389.28 & 0.97 & 0.65 & 446.50 & 442.82 & 0.77 & -2.94 \\
\hline L28 & 465.75 & 331.07 & 1.24 & 0.51 & 398.41 & 392.67 & 0.71 & -2.99 \\
\hline L29 & 616.10 & 512.03 & 0.72 & 1.04 & 564.06 & 561.66 & 0.83 & 2.55 \\
\hline L30 & 627.44 & 504.39 & 0.84 & 1.04 & 565.92 & 562.56 & 0.80 & 2.81 \\
\hline L31 & 601.81 & 454.02 & 1.05 & 0.90 & 527.91 & 522.72 & 0.75 & 1.55 \\
\hline L32 & 563.26 & 338.49 & 1.71 & 0.63 & 450.88 & 436.65 & 0.60 & -2.62 \\
\hline L33 & 618.13 & 420.97 & 1.37 & 0.86 & 519.55 & 510.11 & 0.68 & 1.23 \\
\hline L34 & 425.65 & 340.88 & 0.85 & 0.48 & 383.26 & 380.91 & 0.80 & -4.09 \\
\hline L35 & 704.97 & 504.94 & 1.22 & 1.17 & 604.95 & 596.63 & 0.72 & 4.14 \\
\hline L36 & 473.89 & 327.63 & 1.32 & 0.51 & 400.76 & 394.03 & 0.69 & -4.79 \\
\hline L37 & 456.26 & 362.22 & 0.88 & 0.54 & 409.24 & 406.53 & 0.79 & -3.52 \\
\hline L38 & 489.00 & 400.07 & 0.78 & 0.64 & 444.53 & 442.30 & 0.82 & -1.57 \\
\hline L39 & 620.20 & 479.12 & 0.98 & 0.98 & 549.66 & 545.11 & 0.77 & 1.45 \\
\hline L40 & 521.23 & 380.60 & 1.16 & 0.65 & 450.91 & 445.40 & 0.73 & -2.83 \\
\hline 41 ('Morex') & 536.10 & 486.92 & 0.39 & 0.86 & 511.51 & 510.92 & 0.91 & 3.09 \\
\hline 42 ('Steptoe') & 617.68 & 356.55 & 1.81 & 0.73 & 487.11 & 469.29 & 0.58 & -3.55 \\
\hline LSD (0.05) & 131.76 & 109.78 & 0.61 & 0.35 & 111.94 & 111.55 & 0.142 & 4.74 \\
\hline
\end{tabular}

under non-stress condition was showed between L35, L34 and L37.

Of the 45 cultivated lines used in this study, L5, L7, L8, L10 and L13 had the lowest values of SSI as well as the highest values of YSI and were suggested as the most drought-tolerant lines under drought-stress. These lines showed highest and lowest performance under stress and under non-stress conditions, respectively. YSI evaluates the performance under stress condition of a genotype relative to its non-stress performance, hence the lines with a high 
Table 4. Simple correlation coefficients of stress indices with grain yield of barley doubled haploid lines at Mahabad and Miandoab stations in two consecutive years (2013-2014). Yp, grain yield under non-stress conditions ( $\mathrm{g} \mathrm{m}^{-2}$ ); Ys, grain yield under stress conditions $\left(\mathrm{gr} \mathrm{m}^{-2}\right)$; SSI, stress susceptibility index; MP, mean productivity; GMP, geometric mean productivity; STI, stress tolerance index; YSI, yield stability index; SI, integrated selection index. ${ }^{*}$ and ${ }^{\star *}$, significant at 0.05 and 0.01 probability levels, respectively

\begin{tabular}{|c|c|c|c|c|c|c|c|c|c|c|}
\hline \multirow[b]{2}{*}{ Indices } & \multicolumn{2}{|c|}{$\begin{array}{c}\text { Averaged over years } \\
\text { and locations }\end{array}$} & \multicolumn{2}{|c|}{ Miandoab 2013} & \multicolumn{2}{|c|}{ Mahabad 2013} & \multicolumn{2}{|c|}{ Miandoab 2014} & \multicolumn{2}{|c|}{ Mahabad 2014} \\
\hline & Yp & Ys & $Y p$ & Ys & Yp & Ys & Yp & Ys & Yp & Ys \\
\hline SSI & 0.27 & $-0.47^{\star *}$ & $0.32^{\star}$ & $-0.50^{\star \star}$ & $0.41^{\star *}$ & $-0.54^{\star *}$ & 0.12 & $-0.46^{* *}$ & 0.19 & $-0.39^{* *}$ \\
\hline STI & $0.92^{\star *}$ & $0.93^{\star \star}$ & $0.91^{\star \star}$ & $0.89^{\star \star}$ & $0.91^{\star \star}$ & $0.84^{\star *}$ & $0.96^{\star *}$ & $0.94^{\star \star}$ & $0.96^{* *}$ & $0.95^{\star *}$ \\
\hline MP & $0.94^{* *}$ & $0.91^{\star *}$ & $0.93^{* *}$ & $0.89^{* *}$ & $0.90^{* *}$ & $0.85^{\star *}$ & $0.96^{* *}$ & $0.95^{\star *}$ & $0.96^{* *}$ & $0.94^{* *}$ \\
\hline GMP & $0.91^{\star *}$ & $0.93^{\star *}$ & $0.90^{\star \star}$ & $0.91^{\star *}$ & $0.86^{\star *}$ & $0.89^{* *}$ & $0.94^{\star *}$ & $0.96^{\star *}$ & $0.95^{\star *}$ & $0.96^{\star \star}$ \\
\hline YSI & -0.27 & $0.47^{\star \star}$ & -0.29 & $0.48^{\star *}$ & $-0.40^{* *}$ & $0.52^{* *}$ & -0.19 & $0.42^{\star *}$ & -0.16 & $0.37^{\star}$ \\
\hline SI & $0.76^{\star *}$ & $0.89^{\star *}$ & - & - & - & - & - & - & - & - \\
\hline
\end{tabular}

YSI are expected to have high yield under both stress and non-stress conditions. In our study, lines with the highest YSI exhibited the lowest and highest performance under non-stress conditions and stress conditions, respectively (for example L10 and L13). The highest values of STI, GMP, and MP were observed for L3, L14, L29, L30 and L35. Thus, they were identified as the most stable and productive lines among the cultivated lines under both environmental conditions. Based on SI index, the highest value belonged to L35, L30, L29, L10 lines and 'Morex' (parental genotype); thus they were recognized as drought tolerant lines (Table 3). Correlation coefficients (for two years and two locations) indicated significantly positive correlation between STI, MP and GMP with each other and with both grain yields under non-stress and stress conditions. Also, a highly positive significant correlation was observed between SI with both yields under non-stress and stress conditions. On the other hand, SSI negatively correlated with both grain yields. YSI index had negative and positive correlations with grain yield under non-stress and stress conditions, respectively (Table 4).

In order to identify tolerant lines, three-dimensional graphs were drawn based on Yp, Ys, STI and SI indices (Fig. 2). These graphs separated the lines into four groups: lines with high yields under both non-stress and stress environments (A group), high yield in a non-stress environment (B group), high yield in a stress environment (C group), and low yield under both non-stress and stress environments (D group). Evaluation of three-dimensional graphs revealed that according to both STI and SI indices lines L3, L6, L10, L11, L14, L18, L21, L24, L29, L30 and L35 were placed in A group. These lines are firstly preferable in yield in non-stress and stress conditions, and are secondly superior for quantitative tolerance indices than others; thus they are recommended as candidate lines for tolerance to drought. However, line numbers L2, L8, L13, L16, L19, L41 and L45 had a high yield in stress condition, but under nonstress condition had a low performance; thus they were placed in C group. L15, L22, L23, L33, L42 and L44 had the highest and lowest yield under non-stress and stress conditions, respectively, thus these lines were identified as drought susceptible lines and were recommended only for favorable environments or regions with adequate water. Consequently, the remaining lines were placed in D group,
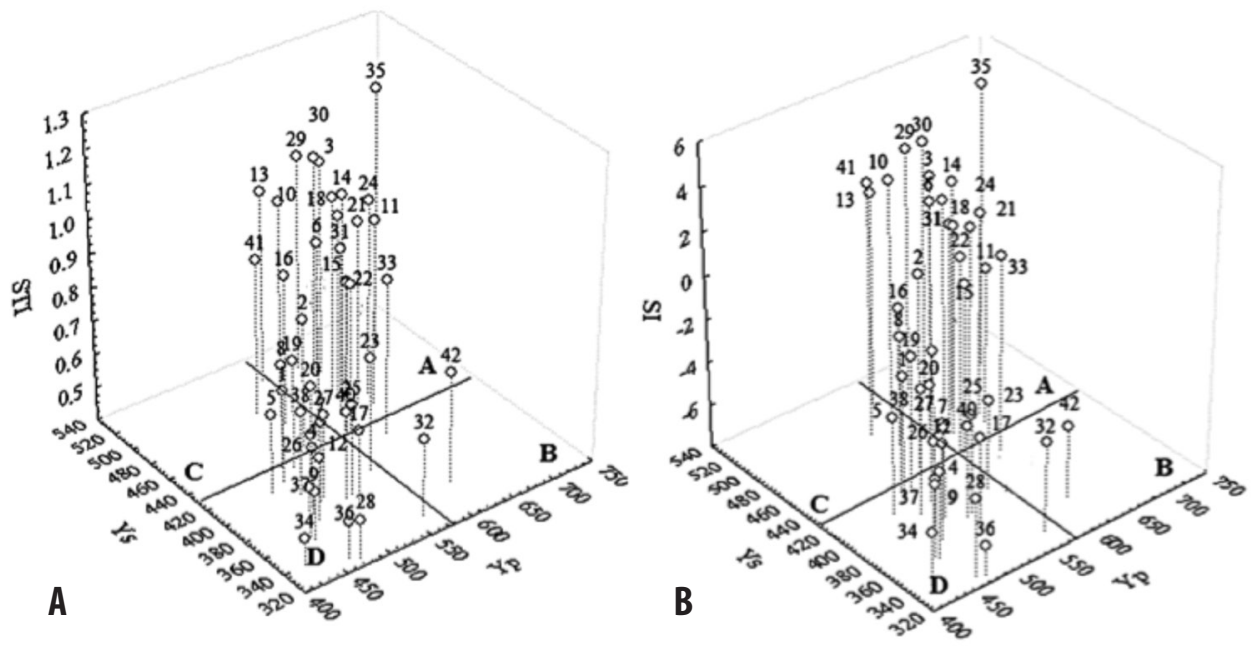

Fig. 2. Three-dimensional diagram for identifying drought-tolerant lines based on grain yield ( $\left.\mathrm{g} \mathrm{m}^{-2}\right)$ under non-stress (Yp) and stress (Ys) conditions as well as the stress tolerance index (STI; A) and integrated selection index (SI; B). 


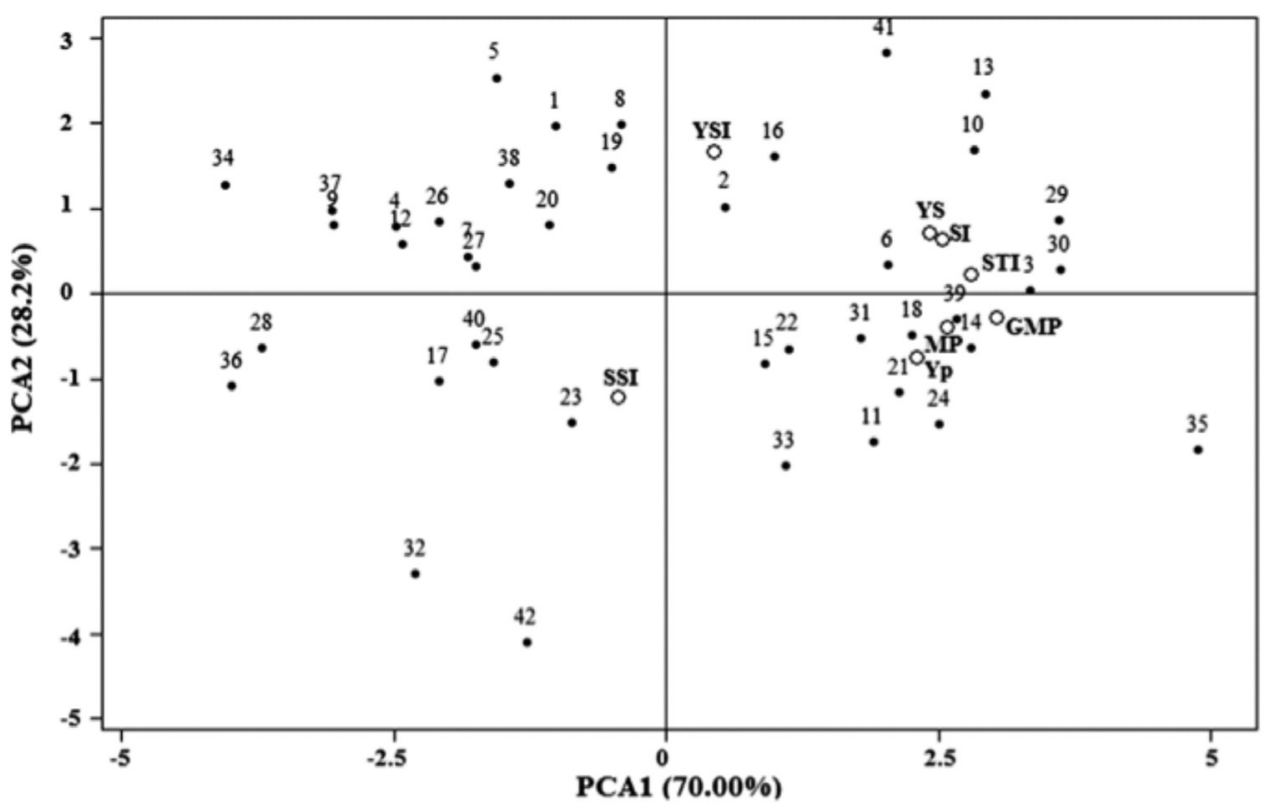

Fig. 3. Biplot drawn based on the first two components obtained from PCA using the stress susceptibility index (SSI), mean productivity (MP), geometric mean productivity (GMP), stress tolerance index (STI), yield stability index (YSI), integrated selection index (SI) and grain yield under non-stress (Yp) and stress (Ys) conditions in barley doubled haploid lines.

as they had low yield under both non-stress and stress conditions. Principal components analysis (PCA) was conducted using the grain yields and drought tolerance indices, and the lines were then subjected to biplot analysis to determine relationships among the indices (Fig. 3). The first component (PCA1) explained $70 \%$ of the total yield variation and showed a positive correlation with both grain yield under non-stress and stress conditions, STI, MP, GMP, YSI, and SI indices. The second component (PCA2) explained $28.2 \%$ of the total yield variation and had a high positive correlation with SSI. A biplot of PCA1 and PCA2 for 40 cultivated lines revealed that 10 lines (L3, L6, L14, L18, L21, L24, L29, L30, L35 and L39) were located near to the best drought tolerance indices (STI, MP, GMP, IS) with high PCA1 but low PCA2 values. On the other hand, the majority of lines with low PCA1 and high PCA2 values were distinguished as susceptible lines. In general, the results of the biplot and three-dimensional graphs demonstrated that lines such as L2, L8, L13, L16, L19, L41 and L45 had the best performance in stressful environments (C group) and lower sensitivity among lines (Fig. 2 and 3).

\section{Discussion}

Grain yield and its related traits are complex quantitative characters controlled by multiple genes and are highly influenced by environmental conditions (Shi et al. 2009). A highly significant difference was found among the lines for grain yield and agro-morphological traits studied in different environments (combination of year, location and water regime conditions), suggesting that traits which are suitable for an environment may be unsuitable in another environment (Mohammadi et al. 2011). Also, the lines $\times$ year interaction was highly significant for grain yield and other traits, indicating that line performance changed from either one year to another or non-stress to stress conditions. The significant correlation between grain yield under nonstress and stress environments (Fig. 1) suggested that a high potential yield under optimum conditions does not necessarily result in enhanced yield under a stress conditions. Therefore, indirect selection for a droughtprone environment based on the results of optimum condition will be efficient (Mohammadi et al. 2011).

Our finding showed selection of superior lines on the basis of each indicator differedr. Khalili et al. (2012) found that, although selection based on a combination of indices may provide a more useful criterion for improving drought tolerance, correlation analysis between both grain yields (under non-stress and stress conditions) and tolerance indices can be a good criterion for screening the best genotypes and indices. STI, MP and GMP indices positively significantly correlated with grain yield under both conditions. Negative relation between SSI and grain yield under both conditions indicated that selection on the basis of this index decreases grain yield under favorable conditions but increases it under drought-stress conditions. As a remarkable result in the present study, a highly positive significant correlation was shown between SI and grain yield under both non-stress and stress conditions (Table 4), indicating capability of this indicator to discriminate A group lines under stress conditions across different environments. According to three-dimensional graphs, STI and SI show similar results: in both graphs L3, L6, L10, L11, L14, L18, L21, L24, L29, L30 and L35 were placed in A group 
(Fig. 2). Thus, based on SI, it seems that plant breeders can select lines with high yield and suitable agronomic traits for drought-prone condition. The ability of the STI, MP and GMP indices to identify genotypes suitably under both conditions observed in this study is consistent with the results reported by Nouri et al. (2011) with durum wheat, Farshadfar et al. (2012) with bread wheat, Naghavi et al. (2013) with maize, Khalili et al. (2014) with safflower, and Poursiahbidi and Pour-Aboughadareh (2013) with chick pea.

While MP, GMP and STI indices were highly correlated with both yields under non-stress and stress conditions (across the different environments), and among them STI index has been usually accepted for assessing of drought-resistant lines, however these indices ignore other agro-morphological traits related to performance of excellent lines under drought stress. Hence the new selection criterion (SI) considers both yields under nonstress and stress conditions as well as agro-morphological traits; thus it can be more suitable to select lines for unpredicted drought stress. Additionally, the selection of agro-morphological traits as important factors related to grain yield and their weight values to drought tolerance were acquired from the statistical results across multiple environments. Furthermore, as an integrated selection index, the agro-morphological traits related to grain yield were selected as the most important traits that contributed to drought tolerance across eight environments, thus these traits were integrated to derive the final selection criterion. For example, based on this index, when the weight of each trait was defined (Table 1), the number of spikes and plant height indicated negative contributions to the final result, while the 1000-grain weight and peduncle length showed a high positive contribution to the final result, which were consistent with predictions. These agronomic traits are simple criteria for drought tolerance, and using these traits in integrated selection criterion (SI) decreases the risk of selection of tolerant lines. Likewise, Hao et al. (2011) and Khalili et al. (2013) used the integrated selection index (SI) to screen tolerance genotypes of corn and barley under normal and stress conditions, respectively. Principal components analysis showed that PCA1 and PCA2 explained $98.2 \%$ of the total yield variation, hence the first and second component were named as yield potential and stress susceptibility, respectively. Accordingly, biplot graph (Fig. 3) demonstrated ten lines L3, L6, L14, L18, L21, L24, L29, L30, L35 and L39 nearly located to the best drought tolerance indices (STI, MP, GMP, SI) with high PCA1 and low PCA2 scores.

Drought tolerance is not often discussed as an independent character by plant breeders because tolerance mechanisms can be fairly general and polygenic in nature. Therefore, the demand to screen for tolerance has encouraged plant breeders to look for a reliable index. Based on grain yield, yield components and drought tolerance indices doubled haploid lines numbers L3, L18, L29 and L35 were superior to others, thus they can be recommended as candidate lines for improvement of drought tolerance in other genotypes.

Moreover, similar to STI, MP and GMP, there was positive and high significant correlations between SI and grain yield under both conditions. Consequently, according to our findings, SI index, similar to MP, GMP and STI indicators, can be efficiently used to screen drought-tolerant lines and also to detect superior lines for both non-stress and stress field conditions across multiple environments.

\section{Acknowledgements}

Sincere gratitude goes to the Department of Agronomy and Plant Breeding, Tehran University for providing plant materials. Special gratitude also goes to Miandoab Agricultural Research Station and Research Station of Mahabad Payame Noor University for providing experimental sites and technical assistances.

\section{References}

Betran F.J., Beck D., Banziger M., Edmeades G.O. 2003. Genetic analysis of inbred and hybrid grain yield under stress and non-stress environments in tropical maize. Crop Sci. 43: 807817.

Bouslama M., Schapaugh W.T. 1984. Stress tolerance in soybean: 1. Evaluation of three screening techniques for heat and drought tolerance. Crop Sci. 24: 933-937.

Ceccarelli S. 1987. Yield potential and drought tolerance of segregating populations of barley in contrasting environments. Euphytica 40: 197-205.

Ceccarelli S., Grando S. 1991. Selection environment and environmental sensitivity in barley. Euphytica 57: 157-167.

Choo T.M., Reinbergs E., Kasha K.J. 1985. Use of haploids inbreeding barley. Plant Breed. Rev. 3: 219-252.

Clarke J.M., De-Pauw R.M.Townley-Smith T.M. 1992. Evaluation of methods for quantification of drought tolerance in wheat. Crop Sci. 32: 728-732.

Dorostkara S., Dadkhodaie A., Heidar B. 2015. Evaluation of grain yield indices in hexaploid wheat genotypes in response to drought stress. Arch. Acker. Pfl. Boden. 61:397-413.

Farshadfar E., Poursiahbidi M.M., Pour-Aboughadareh A.R. 2012. Repeatability of drought tolerance indices in bread wheat genotypes. Int. J. Agric. Crop Sci. 13: 891-903.

Fernandez G.C.J. 1992. Effective selection criteria for assessing plant stress tolerance. In: Kuo C.G. (ed). Proceedings of the international symposium on adaptation of vegetables and other food crops in temperature and water stress. Chapter 25. 13-16 August 1992. Taiwan, Taiwan, pp. 257-270.

Fischer R.A., Maurer R. 1978. Drought resistance in spring wheat cultivars. Part 1: grain yield response. Austr. J. Agric. Res. 29: 897-912.

Gavuzzi P., Rizza F. Palumbo M., Campaline R.G., Ricciardi G.L., Borghi B. 1997. Evaluation of field and laboratory predictors of drought and heat tolerance in winter cereals. Can. J. Plant Sci. 77: 523-531.

Hao Z., Li X.H., Su Z.J., Xie C.X., Li M.S., Liang X.L., Weng J.F., Zhang D.G., Li L., Zhang S.H. 2011. A proposed selection criterion for drought resistance across multiple environments 
in maize. Breeding Sci. 61: 101-108.

Khalili M., Naghavi M.R., Pour-Aboughadareh A.R., Talebzadeh S.J. 2012. Evaluating of drought stress tolerance based on selection indices in spring canola cultivars (Brassica napus L.). J. Agric. Sci. 4: 78-85.

Khalili M., Pour Aboughadareh A.R., Naghavi M.R., Mohammad Amini E. 2014. Evaluation of drought tolerance in safflower genotypes based on drought tolerance indices. Not. Bot. Hortic. Agrobot. 42: 214-218.

Lin C.S., Binns M.R. 1988. A superiority measure of cultivar performance for cultivar $\times$ location data. Can. J. Plant Sci. 68: 193-198.

Minitab 16 Statistical Software. 2004. [Computer software]. State College, PA: Minitab, Inc. (www.minitab.com)

Mohammadi R., Sadeghzadeh D., Armion M., Amri A. 2011. Evaluation of durum wheat experimental lines under different climate and water regime conditions of Iran. Crop Pasture Sci. 62: 137-151.

Naghavi M.R., Pour-Aboughadareh A.R., Khalili M. 2013. Evaluation of drought tolerance indices for screening some of corn (Zea mays L.) cultivars under environmental conditions. Not. Sci. Biol. 5: 388-393.

Nouri A., Etminan A., Teixeira D.A., Silva J.A., Mohammadi R. 2011. Assessment of yield, yield-related traits and drought tolerance of durum wheat genotypes (Triticum turgidum var. durum Desf.). Austr. J. Crop Sci. 5: 8-16.

Pour Aboughadareh A.R., Naghavi M.R., Khalili M. 2013. Water deficit stress tolerance in some of barley genotypes and landraces under field conditions. Not. Sci. Biol. 5: 249-255.

Pour Siahbidi M.M., Pour Aboughadareh A.R. 2013. Evaluation of grain yield and repeatability of drought tolerance indices for screening chickpea (Cicer aritinum L.) genotypes under rainfed conditions. Iranian J. Genet. Plant Breed. 2: 28-37.

Pour Siahbidi M.M., Hoseinzadeh J., Pour Aboughadareh A.R., Bazdar A., Besati H., Naseri-Rad H. 2013. Character association and path analysis of soybean (Glycine max L.) genotypes under water deficit stress. Int. J. Biosci. 10: 126-132.

Rosielle A.A., Hamblin J. 1981. Theoretical aspects of selection for yield in stress and non-stress environment. Crop Sci. 21: 943-946.

Saba J., Moghaddam M., Ghassemi K., Nishabouri M.R. 2001. Genetic properties of drought resistance indices. J. Agric. Sci. Technol. 3: 43-49.

SAS Institute. 1987. SAS/STAT USER'S GUIDE. v. 9.1. SAS Inst Inc., Cary, NC, USA.

Shi J., Li R., Qiu D., Jiang C., Long Y., Morgan C., Bancroft I., Zhao J., Meng J. 2009. Unraveling the complex trait of crop yield with quantitative trait loci mapping in Brassica napus. Genetics 182: 851-861.

Sio-Se Mardeh A., Ahmadi A., Poustini K., Mohammadi V. 2006. Evaluation of drought resistance indices under various environmental conditions. Field Crops Res. 98: 222-229.

STATISTICA Statistical Software. 2007. STATISTICA data analysis software system. v.8. Sta Stof Inc., North Melbourne, Australia. 